\title{
Acute Myocardial Infarction Due to Aortic Dissection
}

\author{
Jung-Ju Sir ${ }^{1}$, Yong-In Kim ${ }^{2}$, Wook-Hyun $\mathrm{Cho}^{1}$ and Suk-Koo Choi ${ }^{1}$
}

Key words: aortic dissection, myocardial infarction, cardiac tamponade

(Inter Med 48: 173, 2009)

(DOI: 10.2169/internalmedicine.48.1726)

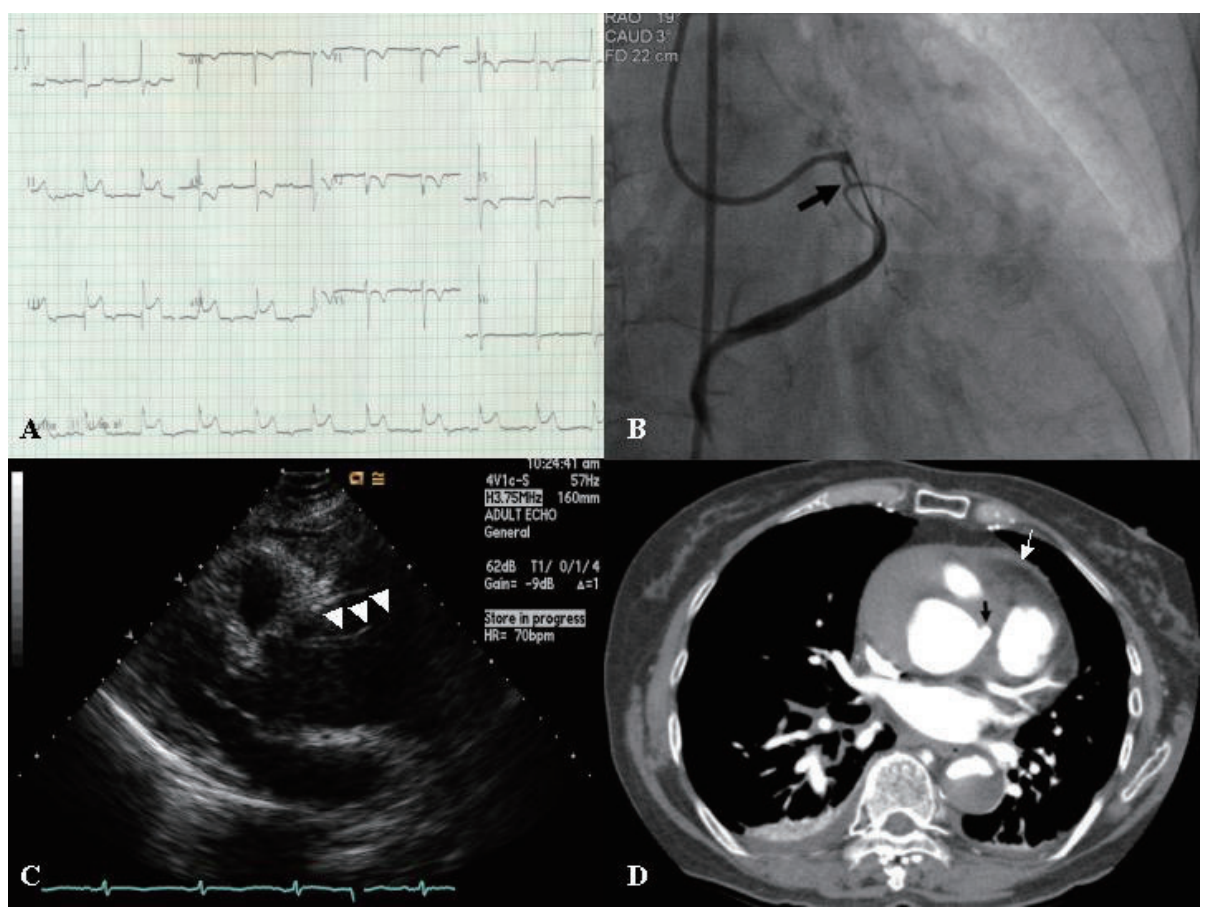

Picture

A 67-year-old hypertensive woman presented with sudden-onset back pain radiating to the anterior chest. Electrocardiogram showed complete atrioventricular block with a marked ST-segment elevation in the inferior leads suggesting acute inferior myocardial infarction (Picture A). Emergent coronary angiography revealed a severely narrowed proximal portion (arrow, Picture B) of the right coronary artery (RCA) which anomalously originated from above the left coronary sinus (Picture B). After stenting of the proximal RCA was performed, the ST-segment was normalized. Transthoracic echocardiography showed the intimal flap (white arrows, Picture C) on the ascending aorta and computed tomography (CT) confirmed the diagnosis of Stanford type I dissecting aortic aneurysm affecting the RCA (black arrow, Picture D) and small amount of hemopericardium (white arrow, Picture D). She developed cardiac arrest due to cardiac tamponade and was successfully resuscitated by cardiac massage with emergent pericardiocentesis. In spite of emergency aortic replacement with Dacron graft and coronary arterial bypass grafting, she suffered from serious neurological sequelae.

\footnotetext{
${ }^{1}$ Department of Internal Medicine, Cardiovascular Center, Inje University Seoul Paik Hospital, Inje University, Seoul, Republic of Korea and ${ }^{2}$ Department of Cardiovascular and Thoracic Surgery, Cardiovascular Center, Inje University Seoul Paik Hospital, Inje University, Seoul, Republic of Korea

Received for publication September 29, 2008; Accepted for publication October 21, 2008

Correspondence to Dr. Jung-Ju Sir, seo0515@medimail.co.kr

(C) 2009 The Japanese Society of Internal Medicine Journal Website: http://www.naika.or.jp/imindex.html
} 